De cometjes, ${ }^{1}$ ) coopluijden encle swarte dienaers, die in Masulipatnam lijwaten ende andere dingen aen de Comp ${ }^{\circ}$ vercopen, zullen van alles aen den Heer betalen twee ende een halff ten hondert eens, zonder buijtendien in eenige andere tollen gehouden te zijn, waerin niet begrepen werden de kleden ende coopmanschappen die 's Comps eijgen ende op Palicoll, Petapoelij, Daetcheron ende andere plaetsen int landt gekoght zijn ${ }^{2}$ ) en nogh jngekoght zullen werden; maer desellve sullen van alle lasten bevrijt blijven ende zonder eenige verhinderingh in 's Comps logie tot Masulipatnam affgebraght worden. Dogh ingevalle bevonden wordt, dat de coopluijclen, dienaers, comities ${ }^{3}$ ) offte ook de Hollanders sellve haer eijgen goederen om dese $21 / 2$ ten hondert niet te betalen onder die van de Comp ${ }^{\circ}$ sluijken of fte zoeken te sluijcken, dat sall clese vrijheijt van met $2 \frac{1}{2}$ ten hondert volcomentlijck te kunnen bestaen daermede werden verbroken ende der vollen tollen ende andere lassten van kleden zullen moeten werden betaellt, als de maniere ende van outs gebruijckelijck is. Van alle $t$ welcke voorstaet sall ick maken dat d'E. Heer Gouverneui Generael kennisse werdt gedaen.

\title{
CCVIII. ARAKAN.
}

\section{Maart 1653. $\left.{ }^{*}\right)$}

$\mathrm{Na}$ het ferman in 1643 door den beheerscher van Arakan aan de O. I. C. verleend, (Corp. Dipl., I, bldz. 413) zijn de betrekkingen met dit rijk niet steeds aangenaam gebleven. Van beteekenis voor ons doel zijn zij in elkgeval niet. In 1649 waren gezanten van Arakan in Batavia. Deze werden met den opperkoopman Heijnsbroek naar hum land teruggezonden. Heijnsbroek had in last, satisfactie te cischen „,wegens het tiramnicq tractement, haare (der O. I. C.) dienaeren aangedaan". Dit hielp niet en in 1650 werd naar Arakan gezonden ,een kleijn oorlogs-esquader om revange te nemen" en „om teffens parttye slaven van daar te halen, waaraan men gebrek

1) Komati, een koopman, handelaar, opkooper vooral bij de wevers van kieedjes, welke zij in grootere partijen verkoopen. (Hobson-Jobson, p. 237, s.. Comaty). Zij vormden een soort gilde.

2) Dus die direct gekocht zijn zonder tusschenkomst der tusschenhandelaren.

3) Vergelijk Hobson-Jobson, t. a. p., bewijsplaats 1679.

4) Uit het Contractboek. - Bij Valentijn, V, I, Choroannandcl, bldz. 143, v.v. is het zeer verkort en onvolledig ongenomen, evenals in Daghregistor 1653, Lidz. 100, v. 
hadde". De koopman David Verdonk werd in 1652 tot ,opperhoofd" bcnoemd (Vg1. Valentijn, Choromandel, bldz. 145) en 27 Sept. 1652 beslout men, van de 123 gevangene 68 naar Arakan te zenden en ,teegens de onse te verwisselen" (Realia, I, Leiden, Kolff, 1882, bldz. 52). - Dit gebeurde nu bij de zending-Goossens. De koopman Joan Goossens kwam 15 Januari 1653 bij Arakan aan en wist na lang onderhandelen de volgende ,articulein". toegestaan te krijgen van den jongen "Coningh”, die „soo lange noch syn volle verstandt niet en heeft, op den duym der grooten wordt gedraeyt, dewelcke meestal nieuwelingen en uyt het stof, om soo te seggen, opgetrocken sijnde, van een seer eijgenzinnich, begeerich ende arghwanigh humeur gedreven worden". (Dagh-Register 1653, bldz. 97-103; zie ook: bldz. 113, v.

Grootmaghtigen vorst Seijnda Zudremo Raza ${ }^{1}$ ) Coninck van Arracan, keijzer van Bengala, ende Heer over veell grote Coninckrijken ${ }^{2}$ ) etc".

De poincten ende artijculen, welck tot volltreckingh ende uijtvoering mijner jegenwoordige legaetschap nedrigh aen UE. Conincklijcke Maijesteijt hebbe te versoeken ende volgens ordre ende last van mijn Heeren ende principalen met UE. Maijesteijt magh aen te gaen ende besluijten, zouden ten principalen bestaen int volgende.

1.

Eerstelijck dat alle voor desen wedersijts gepasseerde actien noijt weer opgehaellt, maer vergeten en uijt der gedaghten uijtgeroeijt werde in maniere of $\hat{f}$ noijt geschiet ware.

2.

Ten anderen aenstonts te, doen restitutie onzer Nederlanderen, bestaende in seven man, jonghts omtrent Ougelij ${ }^{3}$ ) op d'Ganges bij onversiens overrompelen van een onzer chialoupen naer Arracan vervoerdt. Warentegen Uwe Maij ${ }^{\text {ts }}$ met den eersten zullen toecomen

1) Tsandathudamma (Radza) (1652-1684), bij Stokvis, Manucl, I, bldz. 333. Vgl. ook Phayre, History of Burma, p. 178, 180, die hem noemt Sânda Thudammâ. Deze vorst was nog slechts kort geleden op den troon gekomen en een jongen van 13 of 14 jaar (Dagh-Register, 1653, bldz. 98).

־) Goossens vleit den vorst van Arakan: een captatio benevolentiae. Deze toch was geen Keizer van Bengalen, al deden de bewoners van Arakan dikwijls strooptochten in dit door gouverneurs bestuurde deel van het rijk der GrootMogols en hadden zij deelen daarvan tijclelijk in bezit. Vgl. Dagh-Register 1644-1645, bldz. 58. Evenmin was Arakan's „Koning” heer over veel groote koninkrijken. Vg1. Corp. Dipl., I, sub voce Bengalen. - Zie ook Phayre, Buima, p. $171 \mathrm{ff}$. Trouwens in het antwoord des Konings op Goossens' voorstellen is ook geen sprake van al dit noois. Wel was Arakan met Bengalen in deze dagen eens weer o1 voet van oorlog. Vgl. art. 3 dezer voorstcllen.

3) Hoegli. 
alle $t$ volck van die bij Sieur Heijnsbroeck als cocquen ${ }^{1}$ ) naer Batavia vervoerdt ende nogh int leven zijn, bestaende in in een nomber van 123 coppen, zoo mans als vrouwen [en] kindieren, waervan present 63 medebrengen. ${ }^{2}$ )

3.

Strickt verbot aen UE. Maij ${ }^{\text {ts }}$ armada, van onse vaertuijgen offte chaloupen ter rede Pipelij, op (l'reviere Ganges ${ }^{3}$ ) off ellders rescontrerende vrij en ongemollesteerdt te laten varen op hooge straffe tegens d'fauteurs, bij Uwe Maijt daertoe stellen encle promptelijck te doen executeren.

4.

Dat ons schipp offte schepen ter comste datelijck met ervaren loots on d'selve binnen ende gielias ${ }^{4}$ ) on op te boughsjacren ${ }^{5}$ ) gesecourcerdt werden.

5.

Dat Haer Edeles ${ }^{6}$ ) brieven aen Uwe Maij ${ }^{t}$ comende bij onsen Capiteijn, ${ }^{7}$ ) d'selve datelijck overhandight mogen werden zonder 3 à 4 weeken off eenigen tijt [in] de logie te moeten bewaren als off daer niet zonderlings aen gelegen en t'sellve bij Uwe Maij"s onaengenaem ware.

6.

Oock wanneer den Cap tusschen tijcle $\mathrm{U}_{w e} \mathrm{Maij}^{\mathrm{is}}$ te spreeken, ijets te versoeken offte voor te dragen heefft, dat d'zellve gelicentieerdt werde, Uwe Maij ${ }^{\text {ts }}$ zulx mondelinge bekent te maeken, hetzij bij audientie int openbaer offte als Uwe Maijt geen publieque audientie is gevende, dat des-niet-min onzen Cap" om in de binnenpas ${ }^{8}$ ) te compareeren licentie mogh becomen ende gehoor verleent werden, wandt soo sulx genegen zijn bij geschriffte aen Uwe Maij ${ }^{\circledR}$ te verreghten, schoon eerlijcke ende grote schenkagie aen UE. Maij ${ }^{t}$

1)?

2) Zie hiervoór, bldz. 54

3) Vgl. Corp. Dipl. I, bldz. 285, noot 1. - Pipeli aan een der nevenrivierein van de Ganges. (Zie cok Valentijn, Choromandel, bldz, $161 \mathrm{cn}$ aldaar de Nicuwe Kaarte van .... Bengalen).

4) Schuiten, lichte vaartuigen.

5) Boegseeren.

6) Van den Gouverneur-Generaal (en Raden van Indië).

T) Den vertegenwoordiger der O. I. C. in Arakan.

s) ? 
principalen ${ }^{1}$ ) ende vordere officieren als dienairen presenteren en verstercken, eghter niets ten voordeele ve:reghten nogh het versoeck ${ }^{W}$ we Maij ${ }^{t}$ te vooren is comende, maer tot onzen groten naclele de schrifften aghter de hant gehouden ende verduijstert werden, gelijck voor desen onse residenten veellmalen wedervaren is.

7.

Dat wij in alle Uwe Maij ${ }^{\text {ts }}$ landen ende plaetsen zoo in Arracan als in Bengala te water ende te lande, nergens uijtgesondert, een vredige en onbecommerde excercitie van negotie sullen genieten in alle zodanige goederen ende coopmanschappen als slaven, rijs, wasch etc $^{n}$, die op ijder plaetse comen te vallen ende ons oirbaer zijn, gene uijtgesondert van wadt nature d'zellve ook moghten wesen, zonder dat gehouden zijn eenige schilltwaght offte spion ontrent d'logie te gedogen.

8.

Dat wij sullen mogen negoteeren, handelen ende corressponderen met alle zodanige personen, $\mathrm{t} z \mathrm{ij}$ van hoge offte lage qualiteijt, als ons goedtdunken zall en te rade werden, zonder gelijck voor desen meer malen te tijde van $\operatorname{Losclosij}^{2}$ ) ende andere vermogende zij geschiet, cns te constringeren ende op te dringen, eenige goederen ende die ten diersten prijse uijt hare handen alleen naer hun welgevallen te moeten copen, daer wij se anders bij andere gemeene persoonen martgangh tot minderen prijse conden becomen, daarbij clan niet alle ${ }^{3}$ ) grote schade hebben geleden, maer ook vele quade uijtstaende schullden veroorsaeckt, behallven dat door tlangh nalopen de schepen ter behoorlijcker tijt niet zijn gedepecheerdt connen wercien maer met groote veraghteringh onzes dienst hebben moeten tardeeren. Ook is hier uijt ontstaen, dat veele gemene ende sobre Iuijden, die onse woningh frequenteerden, het een en $t$ ander met ons handelende offte dagelijckx behoefftigheden te coop brengende, zeer schandelijck zijn getracteerdt geworden, zommegen affpersende eenige gelltboeten, andere straffende aen de lijve, met geeselen, met vingeren aen handen en voeten afftehouwen ende met eeuwige gevanchenissen.

9.

Niet alleen dat op alle plaetsen ende alle goederen liberlijck mogen

1) Voornaamste ambtenaren.

2) Mij is niet gebleken wat hiermede bedoeld wordt.

3) Alleen? 
negotieren. maer sulx vrij ende buijten lassten van thollen ende raderijen offte t'sionkans, ${ }^{\mathbf{1}}$ ) hoe sulx moghte genoemt werden, zoo well van de aenbrengende goederen ende coopmanschappen als mede zodanige als daer $\mathrm{t}$ zij in Bengala offte Arracan etc" ende ter wadt plaetse hoe die genaemt moghen wesen ende onder Uwe Maij ${ }^{\text {ts }}$ gebiet sorteerende, zullen comen te negotieren ende vervoeren, gelijck voor desen ook well gestipuleert en geaccordecrt sijn geweesst, maer egter doorgaens verhinderingh in geleden.

10.

Dat onze schepen naer ons wellgevailen mogen lossen en laden zonder eenige visite offte oppassers te gedoogen noghte subject te wesen, insonderheijt op $t$ schepen ${ }^{2}$ ) der slaven, maer dat sellve mogen incoopen ende affschepen gelijck tot den jare 1638 in observantie zij geweest. Daer ${ }^{3}$ ) is eenelijck, wanneer de slaven geinbarcqueerdt wierde, d'sellve zijn gevisiteerdt geworden door t volck des $t$ coutow $^{\mathrm{r}}{ }^{4}$ ) ende een van sig aghtmas; $;^{5}$ ) ende dat om geen mancquijns ${ }^{6}$ ) off die d'jnlandsche tale spreken conden en omtrent d'7 jaer in Uwe Maij"s rijclis geweest zijn te vervoeren. D'zulcke vinde[nde] zijn sanderen daeghs andere in deszelffs plaets gegeven. Ende niet gelijck zedert den jare 1643, dat extraordinaris visiten hebben moeten gedoogen, dat in plaetse d'sellve in voortijde gelijck geseght bij t volck des coutewaells ende een van siaghtmas op de schejen zijn gevisiteert ende maer ondervraeght wierde, hoe langh genomen en off de Moorsche tale ${ }^{\top}$ ) conden, zoo heefft men doen daer nogh bij gevoeght gehadt ende sicque crangs sougrij ${ }^{s}$ ) ende het volck van anharij; ${ }^{9}$ ) ende laten affnemen die zeijclen maer $t$ minste

1) Tollen.

2) Inschepen?

3) Uit het stuk, hierachter verkort volgende, blijkt, dat moet worden gelezen: ,dlat".

4) Moet zijn: „coutewael” (zie beneden). - Catwal, catual: Ambtenaar belast met marktaangelegenheden, met de politie enz. (Corp. Dipl., I, bldz. 487).

5) Het hierachter genoemde stuk heeft: ,roos ende zanghma”. Vg1. DaghRegister 1653, bldz. 99, waar gesproken wordt van "de Coutewael ende Roos" en van ,Sanghmao, 's Coninx thresorier".

6) Bewoners van Myohaung, de hoofdstad??? Vg1. Gascticcr, V, 392.

T) Wordt hier natuurlijk gezegd voor de in Arakan inheemsche taal. Vgl. Corp. Dipl. I, bldz. 414. Het Arakaneesch is een „dialect” van het Burmaneesch (Hunter, Gazettecr, New edition, IX, p. 137). Men wilde blijkbaar niet, dat de eigenlijke Arakaners als slaven werden opgekocht en weggevocrd.

s) Vgl. Dagh-Register 1653, bldz. 99.

9) ? 
handtwerck te connen, waervoor dan een deell, oudt, verleemt, ${ }^{1}$ ) manck en caduck volck, nae drije vier jae vijff clagen waghtens, in plaets moesten aennemen, dat ons in de negotie grotelijckz deden veraghteren. ${ }^{2}$ )

\section{1.}

Dat onze gellden volgens valeur soo in wisselingh van d'allhier gangbare munte als tegens trocque van coopmanschappen zonder daerop te verliezen mogen aengenomen werden.

\section{2.}

Dat ons een bequame ruijme ende well gelegen plaetse om onze logie ende packhuijsen te setten verleent werden, allwaer geen brant van andere woningen daer onitrent subject zijn.

\section{3.}

Dat wij wegens onzen voor clesen gedane reghtmatigen pretentie ${ }^{3}$ ) eenighsints zij met ter handt stellingh van seekere quantiteijt slaven offte eenige andere te verlene voordeelen naer discretie mogen gecontenteert werden. ${ }^{4}$ )

14.

Dat wij mogen bij verscheijningh voor Uwe Maij ${ }^{t}$ volgens onse gewoonte d'behoorlijcke eerbiedigheijt ende reverentie doen, zonder dat door een coutewael en andere naer hun wellgevallen ende onser groter ongewoonte en vastidie ${ }^{5}$ ) in spot van een jgelijck tot voor den throon van $\mathrm{Uwe}_{w} \mathrm{Maij}^{\mathrm{t}}$ getrocken ende gesleurdt werden. ${ }^{6}$ )

15.

Dat wanneer binnen bij $\mathrm{U}_{w e} \mathrm{Maij}^{\mathrm{t}}$ verschijnen, alltijt onse eijgen

1) Verleeint? = verminkt, gebrekkig (Verdam, Middel-Nederlandsch handz'oordenbock, ('s-Gravenhage, Nijhoff, 1911, sub voce).

) Men ziet, hice gelijk had Marten Isbrants, toen hij waarschuwde tegen dein slavenhandel. (Corp. Dipl., I, bldz. 413).

3) Daghrcgister 1653, bldz. 181, verkort dit aldus: ,dat wy voor onze pretensie om de scharle, die wij voor dezen geleden hadden, behoorlijck contentement mochten genieten".

4) Dit is niet ingewilligd door den vorst van Arakan. Het artikel komt althans niet voor in het volgende stuk. Zie trouwens Dagh-Register 1653, bldz. 161: de vorst zeide ,dat wij de schade, die ons voor deze van sijn volck geleden hadden, behoorden te vergelijcken met het gene sijne landen en onderdanen naderhant door de gepleegde hostiliteijten (van 's Compagnie's zijde) hebben moeten uijtstaen".

5) Afkeer.

$\left.{ }^{6}\right) \mathrm{Vgl}$. de korte beschrijving van dit vernederende eerbetoon bij Valentijn, Choromandel, bldz. 143 . 
taellman off toilck dight bij ons mogen hebben om daerdoor Uwe $M a i^{t}$ tgeen willen versoeken bekent te maken.

16.

Dat Uwe Maijt ons tot alis voornoent verhaellcle vrije en onbecommerdt negotie, zoo hier als in Bengala, bondige en vaste firmans, waerop ons mogen russten, gunstelijck sult gelieven te verleenen ende met eenen datelijck door ganslagh ${ }^{1}$ ) over $t$ geheele landt $t$ zellve laten vercondigen ende uijtroepen.

17.

Dat Uwe Maij ${ }^{\mathrm{t}}$ ons mede doe ter handt stellen al de kinderen, voor desen door onze Nederlanders bij de jnlandsche vrouwen van tijt tot tijt geprocureerdt, namentlijck. t'kint van Adriaen van der Stell $;^{2}$ ) t kint van Bastiaen Jacobszoon; 2 doghterkens van Jasz. ${ }^{3}$ ) den Engelsman, waervan d'eene getrouwt is; een doghterken van Claes Harmszoon Bisschop.

Dat alle slaven, bij onze residenten voor desen in vrijdom gestellt en daer naer bij $\mathrm{d}^{\prime} \mathrm{Maij}^{\mathrm{t}}$ aen hem getrocken, niet anders wetende off sij 's Comps slaven geweesst, werdende tot oppassers van de paerden en oliphanten stallen gebruijckt, vrij en liber mogen gelargeerdt werden.

Van welcke voorschreven poincten $U_{w e} \mathrm{Maij}^{\mathrm{t}}$ gesint zijnde ons d'zellve in te willigen, versoeken een schrifftelijck contract, zodanigh gespecificeerdt, onder Uwe Maij ${ }^{t}$ zegell geliefft te passeeren ende ons ter handt stellen, op dat daermede $d^{\prime} E d^{\circ}$ Heer Generael mogh verthonen gunt met $\mathrm{U}_{w e} \mathrm{Maij}^{\mathrm{t}}$ geaccordeert ende besloten zij, naer welckers effect onse schepen datelyck tot in den handell zullen laten opconten.

Jn Arracan den 28 Februarij $A^{\circ}$ 1653. Was geteeckent Joan Goesens.

1) Gongslag??? - Het volgende stuk heeft „gonslagh”.

2) Adriaan Van der Stel, den bekende.

3) Het volgend stuk heeft "Jan". 
Specificatie der poincten en artijculen welcke den Koningh van Arracan op 's Comp's gedane voorstell heefft toegestaen en jngewillight namentlijck. ${ }^{1}$ )

2.

Ten anderen restitutie onser Nederlanderen bestaende in ontrent Ouglij op d'Ganges bij onversiens overrompelen van een onzer chaloupen naer Arracan vervoerdt, mits dat daarvan drie hier bij d'logie overblijven tot dat den Maijt resterende van zijn volck zall becomen hebben.

10.

Dat onze schepen naer ons wellgevallen mogen lossen ende laden zonder eerige visite offte oppassers te gedoogen noghte subject te wesen, insonderheijt opt schepen der slaven maer dat dezellve mogen jncopen ende affschepen gelijck tot den jare 1638 in observatie zij geweest dat is, eenlijck wanneer d'slaven g'jmbarcqueert werden d'zellve maer gevisiteerdt zullen worden door $t$ volck des coutowaels, roos ende zanghma, ende dat om geen mancquijns off die de jnlandtsche tale spreken konden en omtrent de seven jaer in Uwe Maij ${ }^{\text {ts }}$ rijck geweesst zijn te vervoeren. D'zulcke vindende, zullen datelijck weer andere in desselffs plaets gegeven werden.

16.

Dat d'Maij' ons mede zall doen ter handt stellen alle de kinderen die door ons sullen aengewesen worden voor desen door onze Nederlanders bij deze inlandtsche vrouwe van tijt tot tijt geprocureerdt waervan voor eerst gespecificeercle staen $\ldots{ }^{2}$ )

Int palleijs des Coninckl. Maijt van Arracan den 22e Maerclt $\mathrm{A}^{\circ} 1653$.

1) Ik neem hier slechts enkele artikelen over. De overige zijn gelijkluidend met Goossens voorstellen.

2) Volgens de namen, die op bldz. 60 zijn genoemtd. 